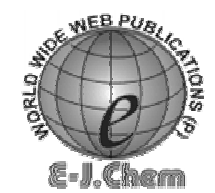

http://www.e-journals.net
ISSN: 0973-4945; CODEN ECJHAO

E-Journal of Chemistry

Vol. 5, No. 2, pp.243-250, April 2008

\title{
Solar Photolysis and Photocatalytic Decolorization of Thymol Blue
}

\author{
FALAH H. HUSSEIN*, AHMED N. ALKHATEEB, \\ and JAMEEL K. ISMAIL \\ *College of Science, Babylon University, Hilla, Iraq. \\ Department of Chemistry, College of Science, Ibb University, Ibb, Yemen. \\ abohasan_hilla@yahoo.com
}

Received 1 July 2007; Accepted 20 September 2007

\begin{abstract}
The photolysis and photocatalytic decolorization of an aqueous propane-2-ol solution of thymol blue(TB) (Phenol, 4,4'-(3H-2,1-benzoxathiol3-ylidene)bis(5-methyl-2-(1-methylethyl)-,S,S-dioxide; Thymolsulfonpthalein) $\left(\mathrm{C}_{27} \mathrm{H}_{30} \mathrm{O}_{5} \mathrm{~S}\right)$,were carried out under natural weathering conditions. Direct photolysis of TB solution of concentration $4.3 \times 10^{-3} \mathrm{M}$ degraded $37.1 \%$ of the colored solution after two hours of solar irradiation, however, the solar photocatalytic decolorization percentage reached $79.04 \%$ and $86.21 \%$ after the addition of zinc oxide and titanium dioxide, respectively, for the same period. The degradation percentages were investigated by monitoring the dye decolorization spectrophotometrically. The decolorization rates of $\mathrm{TB}$ are markedly related with amount of hydroxyl radical formed. A suitable mechanism for the mineralization of TB has been proposed.
\end{abstract}

Keywords: Solar Photolysis and Photocatalytic decolorization, Thymol blue

\section{Introduction}

Arab countries are expected to face water shortages in the near future. Except Iraq and Syria, other Arab countries face serious water scarcity now, a problem which will be difficult ${ }^{1}$ to be solved by 2025 . Although Eritrea and Lebanon are regarded as water stress countries, other countries such as Algeria, Bahrain, Egypt, Jordan, Kuwait, Libya, Morocco, Oman, Palestine, Qatar, Saudi Arabia, Tunisia, United Arab Emirates and Yemen. are Classified as water scarce countries ${ }^{2}$. 
However, the availability of sunlight could recover this black image of water dearth. The direct solar radiation in Arab homeland is ranging from $4.1 \mathrm{kw} \mathrm{h} / \mathrm{m}^{2} / \mathrm{day}$ in Mosul city in Iraq to $6.7 \mathrm{kw} \mathrm{h} / \mathrm{m}^{2} /$ day in Nouakchott, the capital of Mauritania ${ }^{3-4}$. Moreover, sunshine duration ranges between $7.5 \mathrm{~h}$ in Tunsia to $10.7 \mathrm{~h}$ in Egypt ${ }^{3}$. Consequently, the water deficiency, which becomes worse due to the huge industrial consumption of water. Moreover, avoiding the recycling or reusing wastewater in other industries makes the problem more worse. However, investment of the available solar energy for the purpose of purification of industrial wastewater will lead to the dramatic reparation of the anticipated disastrous scarcity of the domestic water.

Decolorization is one of the most important nominated techniques utilized in the treatment of the industrial wastewater .Gizechulska and Morawski ${ }^{5}$ reported that the removal of color from wastes is more important than the removal of other colorless chemicals. However, not all the decolorization processes are suitable for decontamination. The degradation products should be non-toxic or at least less toxic than the degraded original compound ${ }^{6}$.

Recent studies demonstrated that heterogeneous photocatalysis is the most efficient technique in the degradation of colored chemicals ${ }^{7-15}$. These studies used titanium dioxide and / or zinc oxide in the photolysis processes. The band gap for both titanium dioxide and zinc oxide is $(\sim 3.2 \mathrm{eV})$, indicating that their photocatalytic activities are shown only under UV illumination ${ }^{8-10}$. Electrons in the valence band of semiconductors are excited to the conduction band when semiconductors are illuminated with UV radiation, leaving the positive hole in the valence band.

Photosensitization process occurs when a semiconductor mediates the oxidation of colored reagents ${ }^{6}$. In photosensitization, the adsorbed colored compound(s) on the surface of the semiconductor could absorb a radiation in the visible range ${ }^{11-13}$. The excited colored dye $\left(S^{*}\right)$ (in the singlet or triplet state) will inject an electron to the conduction band of the semiconductor ${ }^{16}$.

Advanced oxidation processes (AOPs) concern with the total oxidation of organic and inorganic materials in wastewater by heterogeneous photocatalysis. The hydroxyl group radical $(\mathrm{OH})$; which is formed by the photocatalytic process, where the reaction is illuminated by UV in the presence of a semiconductor, or from the photosensitization processes; will oxidize all the organic to $\mathrm{CO}_{2}$ and $\mathrm{H}_{2} \mathrm{O}$ (mineralization). This is attributed to very strong oxidizing power of. $\mathrm{OH}$ which has the standard redox potential of $+2.8 \mathrm{~V}$.

$$
\begin{aligned}
\mathrm{TiO}_{2}+\mathrm{hv} & \rightarrow \mathrm{h}^{+}+\mathrm{e}^{-} \\
\mathrm{h}^{+}+\mathrm{OH}^{-} & \rightarrow . \mathrm{OH} \\
\mathrm{e}^{-}+\mathrm{O}_{2} & \rightarrow \mathrm{O}_{2}^{-}
\end{aligned}
$$

However, in the presence of a sensitizer, the following reactions will take place:

$$
\text { dye }+\mathrm{h} v \rightarrow \text { (uv or visible }) \rightarrow \text { dye* }
$$

dye* + semiconductor $\rightarrow$ dye.+ e- ( to the conduction band of the semiconductor).

$$
\begin{aligned}
& \text { e- }+\mathrm{O}_{2} \rightarrow \mathrm{O}_{2^{-}} \text {(ads) } \\
& \mathrm{O}_{2^{-}}(\text {ads })+\mathrm{H}_{2} \mathrm{O} \rightarrow \mathrm{OH}-(\mathrm{S})+\mathrm{HO}_{2} . \\
& \text { dye. }+ \text { OH- } \rightarrow \text {.OH }
\end{aligned}
$$

The TB, whose structure is shown in Figure 1, is used as biological stain and $\mathrm{pH}$ indicator. It was demonstrated that the compound can be harmful. Indeed, it is hazardous irritant and permeative substance. Inhalation: may cause irritation to the respiratory tract. Symptoms include coughing and shortness of breath.. Ingestion of large oral doses could cause irritation to the gastrointestinal tract. Skin Contact might cause irritation with redness and pain. Eye contact may cause irritation, redness and pain. 
The present work, aims to study the photolysis and photocatalytic degradation of thymol blue using $\mathrm{TiO}_{2}$ and $\mathrm{ZnO}$ under natural weathering conditions.<smiles>CC1=CC(=O)C(C(C)C)=CC1=C(c1cc(C(C)C)c(O)cc1C)c1ccccc1S(=O)(=O)O</smiles>

\section{Experimental}

Figure1. The structural formula of TB

\section{Materials and Methods}

TB supplied by Fluka with a high purity (99\%) was used as a test colored pollutant. Its structure is shown in Figure 1. It is usually used as $\mathrm{pH}$ indicator and as biological stain. Photocatalyst employed in this study was the titanium dioxide, supplied by BDH Limited with 98\% purity (General purpose reagent GPR). Zinc oxide with $99 \%$ purity, supplied by BDH, is also utilized in this study as photocatalyst. All other chemicals were used without further purification.

TB was analyzed by UV-Visible Spectrophotometer (UV 2100 Unico). The determined wavelength was $565 \mathrm{~nm}$, which is the maximum absorption wavelength. The determined absorption was conducted to a concentration through the Standard- Curve method of dye. The range of the concentration of aqueous propan-2-ol solution (1:1 percentage) was $4.0 \mathrm{X}$ $10^{-6}-5.2 \times 10^{-6} \mathrm{M}$, which was used to conduct the calibration curve in this work.

Experiments were carried out during April and May 2005, over continuous 45 days period. All experiments have been performed at the floor of chemistry department building in Ibb University, in an open atmosphere between 11.00 a.m.-1.00 p.m. Sunlight illumination was accomplished in a $400 \mathrm{~cm}^{3}$ beaker containing $100 \mathrm{~cm}^{3}$ of the TB solution. The sunlight radiation was collected using converging lens with a focal length of $14 \mathrm{~cm}$. In all experiments, $400 \mathrm{mg}$ of the catalyst, anatase or zinc oxide, was suspended using a magnetic stirrer in dye solution. During the irradiation of the reaction mixture, $2 \mathrm{~cm}^{3}$ samples of the reaction mixture were, periodically, withdrawn using a syringe with a long pliable needle. These were centrifuged to separate the solid catalyst .In each case, $1 \mathrm{~cm}^{3}$ of the supernatant was drawn and diluted to $50 \mathrm{~cm}^{3}$ to measure the absorbance at $565 \mathrm{~nm}$, using ultraviolet-visible spectrophotometer, type UV 2100, supplied by Unico Company. The photodegradation percentage of the dye was followed spectrophotometrically by a comparison of the absorbance, at specified interval times, with a calibration curve accomplished by measuring the absorbance, at known wavelengths, with different concentrations of the dye solution.

The experiments were also performed in the absence of the semiconductor in the presence and absence of sunlight. Decolorization efficiency is also calculated from a mathematical equation adapted from measurements of decolorization used before ${ }^{17-18}$.

$$
\text { Decolorization }=\frac{(\text { Absorbance })_{0}-(\text { Absorbance })_{t}}{(\text { Absorbance })_{0}} \times 100
$$

Where (Absorbance) $)_{0}$ is the absorbance at $565 \mathrm{~nm}$ before irradiation and (Absorbance) $\mathrm{t}$. is the absorbance at time $t$. 


\section{Results and Discussion}

Figure 2 shows that $\mathrm{TiO}_{2}$ gives good results compared with $\mathrm{ZnO}$ and in the absence of semiconductor (photolysis). However, no changes in color were observed in the absence of the catalyst and sunlight. The photolysis and photocatalytic degradation of TB were found to be fell in the sequence:

Photocatalytic $\left(\mathrm{TiO}_{2}\right)>$ Photocatalytic $(\mathrm{ZnO})>$ Photolysis

The decolorization of $\mathrm{TB}$ in the presence of sunlight and $\mathrm{TiO}_{2}$ or $\mathrm{ZnO}$ was increased linearly with irradiation time and was found to be equal to $86.21 \%$ in the presence of $\mathrm{TiO}_{2}$ after $2 \mathrm{~h}$ of irradiation and $79.04 \%$ in the presence of $\mathrm{ZnO}$ for the same period.

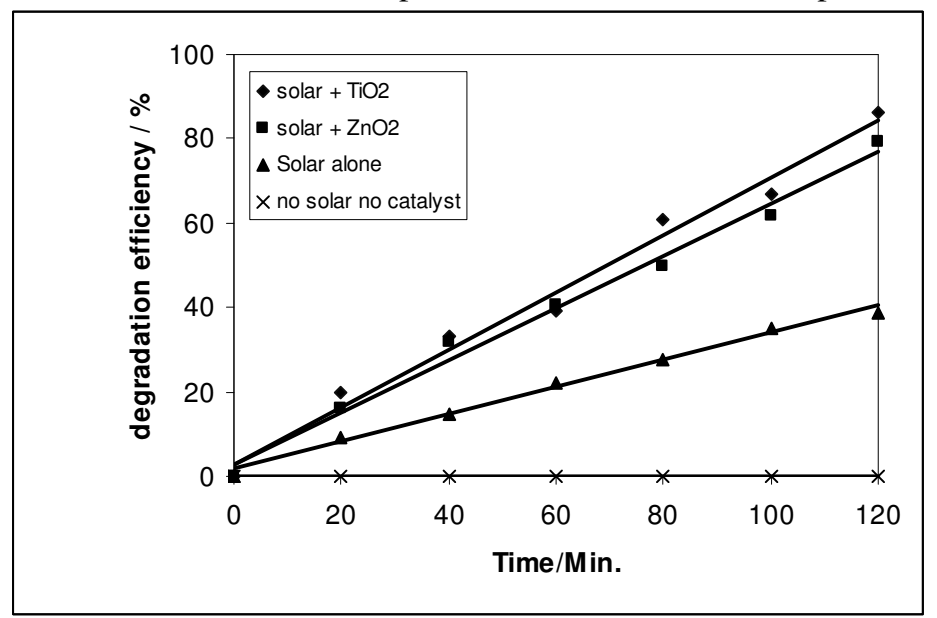

Figure 2. Degradation of TB under different conditions

No decolorization has been obtained in the absence of the sunlight and catalyst. However, in direct photolysis under sunlight process, i.e. in the absence of catalysts, the photolysis was observed to increase linearly with irradiation time to become $37.16 \%$ after $2 \mathrm{~h}$ of irradiation. Comparison between the two methods used for the determination of decolorization efficiency is shown in Table 1.

Table 1. Comparison between decolorization efficiency obtained from the calibration curve and the adapted equation

\begin{tabular}{ccc}
\hline \multirow{2}{*}{ Condition } & \multicolumn{2}{c}{ Decolorization efficiency / \% } \\
\cline { 2 - 3 } & Calibration Curve & Adapted equation \\
\hline Solar $+\mathrm{TiO}_{2}$ & 86.61 & 86.21 \\
Solar $+\mathrm{ZnO}$ & 77.22 & 79.04 \\
Solar alone & 40.08 & 37.10 \\
No solar, no catalyst & 0 & 0 \\
\hline
\end{tabular}

The degradation pattern of the TB could occur via the four main schemes shown in Figures 3-6, respectively, where the attack of the active hydroxyl radical $(\mathrm{OH})$ upon the TB takes place via four suggested positions in the segments of TB mentioned in Figures 2-5. Figure 3 reveals that segment (I) is attacked by the. $\mathrm{OH}$ via the four main routes (a-d). The first route (a) includes the formation of the adsorbed intermediates (Ia), which are ultimately mineralized ${ }^{19}$ to $\mathrm{CO}_{2}$ and $\mathrm{H}_{2} \mathrm{O}$. The second route (b) involves the formation of the dihydroxy intermediate (Ib), which is degraded ${ }^{19}$ to $\mathrm{CO}_{2}$ and $\mathrm{H}_{2} \mathrm{O}$. 
The third route (c) includes the attack of .OH on the isopropyl to form the isopropyl radical (Ic) with the evolution ${ }^{20}$ of $\mathrm{H}_{2} \mathrm{O}$. The (Ic) intermediate is attacked by $\mathrm{O}_{2}$ to give the corresponding peroxyl intermediate (Id), which is degraded ${ }^{20}$ to the alkene (Ie) derivative and $\mathrm{HO}_{2}$.

The fourth route (d) involves the transformation of the $\mathrm{CH}_{3}$ group to the aldehydic group, $\mathrm{CHO}$, to give the intermediate (If), which could be converted to other intermediate products, that are mineralized ${ }^{19}$ to $\mathrm{CO}_{2}$ and $\mathrm{H}_{2} \mathrm{O}$. In addition, the aldehydic product (If) could be attacked by .OH to give the dihydroxy intermediate (Ig), which is degraded ${ }^{19}$ to $\mathrm{CO}_{2}$ and $\mathrm{H}_{2} \mathrm{O}$. Moreover, the intermediate (If) may react with .OH with the elimination of $\mathrm{H}_{2} \mathrm{O}$ to give the isopropyl radical derivative (Ih), which reacts with $\mathrm{O}_{2}$ to yield the peroxyl radical (Ii), which gives the alkene derivative ${ }^{20}(\mathrm{Ij})$ beside. $\mathrm{HO}_{2}$.

Figure 4 demonstrates the degradation main two routes for segment (II). The first route (a) compromises the degradation ${ }^{21}$ of (II) into $\mathrm{CO}_{2}, \mathrm{H}_{2} \mathrm{O}$ and $\mathrm{H}_{2} \mathrm{SO}_{4}$. The second route (b) involves the introduction of . $\mathrm{OH}$ group to the benzene ring to form the intermediate (IIa), which is mineralized ${ }^{21}$ to $\mathrm{CO}_{2}, \mathrm{H}_{2} \mathrm{O}$ and $\mathrm{H}_{2} \mathrm{SO}_{4}$.

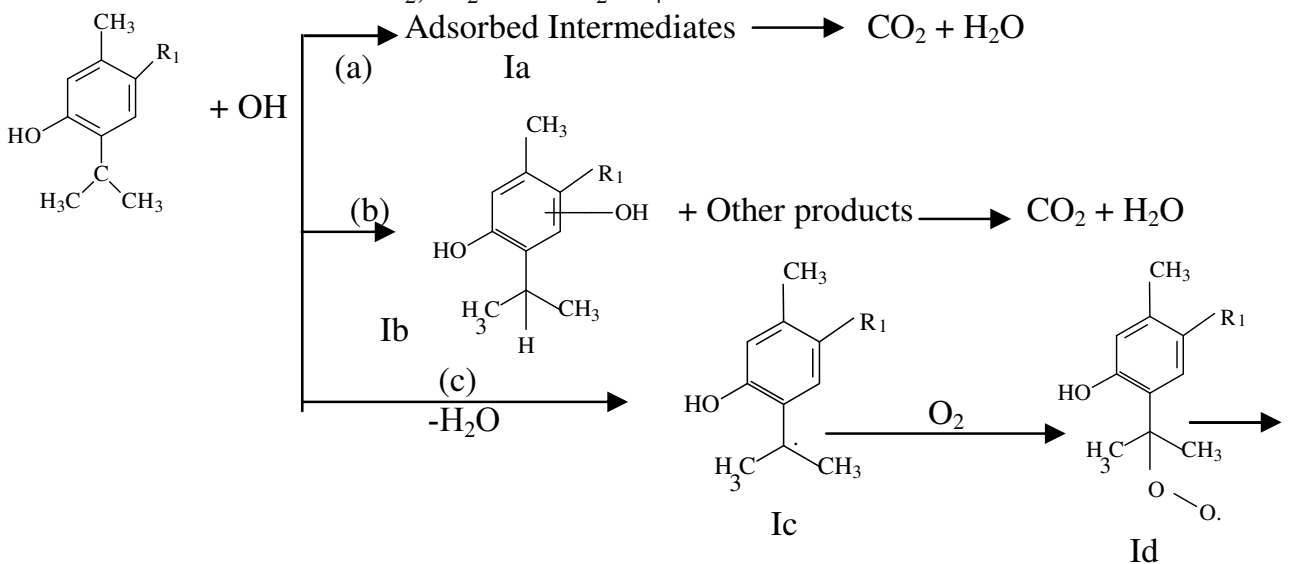<smiles>[R]c1cc(C(=C)C)c(O)cc1C</smiles><smiles>[R]c1cc(C(C)C)c(OC(C)C)cc1C</smiles>

(d)<smiles>[R1]c1cc(C(C)(C)[IH])c(O)cc1C=O</smiles>

Id<smiles>[R]c1cc(O)c(C(C)(C)[15CH3])c(C=O)c1</smiles><smiles>[R1]C1=CC(C(C)C)C(O[C@@H](C)O)C=C1[C@H](C)O</smiles>

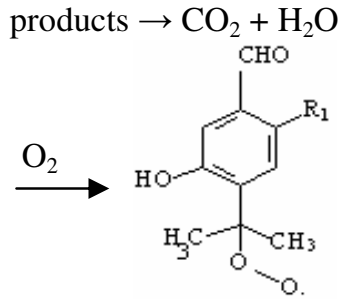<smiles>C=C(C)c1cc(Br)c(C=O)cc1O</smiles>

Ih

Ii

Figure 3. The degradation route of the segment (I). 


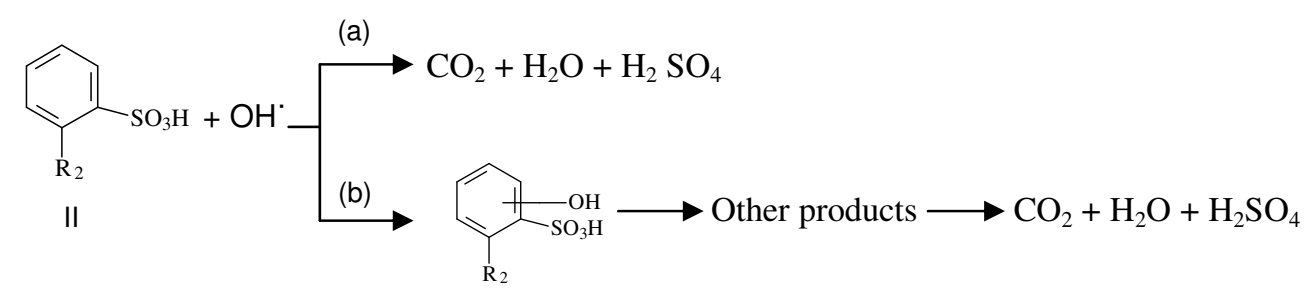

Figure 4. The degradation route of the segment (II).

Figure 5 reveals the main degradation route of the segment (III). Attack on the exodouble bond by. $\mathrm{OH}$ leads to the formation of alkyl radical (IIIa), which reacts with $\mathrm{O}_{2}$ to give the peroxyl radical (IIIb), which is converted to the tetroxide derivative (IIIc) that decompose to the radical (IIId) as well as two molecules of the ketone (IIIe). Moreover, the product (IIId) could be converted to the peroxyl radical (IIIf) that is transformed to the benzoquinone intermediate(IIIg) besides $\mathrm{HO}_{2}$. It is noteworthy to mention that other routes could take place including the attack upon the isopropyl and the methyl groups to give other intermediates such as aldehydic, isopropyl, alkene intermediate which were outlined in the previous degradation routes.

Figure 6 shows the degradation pattern for the segment (IV), which occur through two routes ( $a$ and $b$ ). Route (a) includes the formation aldehydic derivative (IVa), via the attack upon $\mathrm{CH}_{3}$ group by. $\mathrm{OH}$, which is degraded to other products ${ }^{19}$ that lead finally to $\mathrm{CO}_{2}$ and $\mathrm{H}_{2} \mathrm{O}$. Route (b) involves the elimination of $\mathrm{H}_{2} \mathrm{O}$ to give isopropyl radical derivative (IVb); which is oxidized by $\mathrm{O}_{2}$ to yield the peroxyl radical (IVc); that leads finally to the alkene derivative (IVd) and $\mathrm{HO}_{2}$.<smiles>[R3]C([R3])=C1C=C(C(C)(C)[C@H](C)O)C(=O)C=C1C</smiles>

III IIIa

IIIb Tetroxide<smiles>[R]C(C)=O</smiles>

Figure 5. The degradation route of the segment (III). 


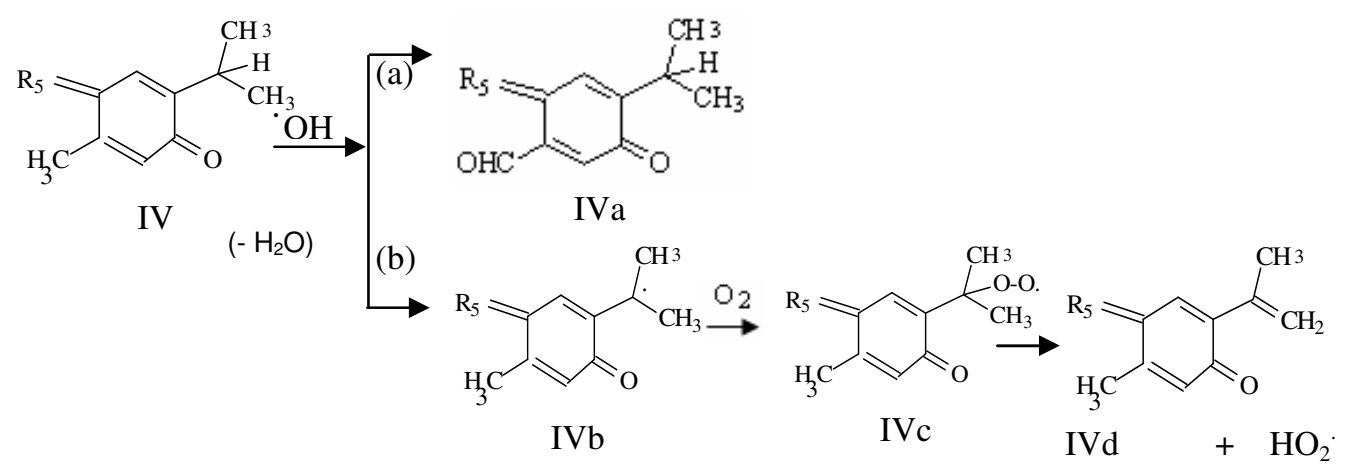

Figure 6. The degradation route of the segment (IV).

It is imperative to mention that the kinetics of the aromatic ring degradation were monitored at the higher wavelength ${ }^{22}$.

\section{Conclusions}

1. Solar energy is essential for photodegradation process of TB. The degradation percent reached $37.1 \%$ after $2 \mathrm{~h}$ of solar irradiation.

2. The percent of photodegradation is more than doubled in the existence of the photocatalyst.

3. The band gap of $\mathrm{TiO}_{2}$ and $\mathrm{ZnO}$ is equal to $\sim 3.2 \mathrm{eV}$, i.e., near ultraviolet irradiation is needed to excite the electrons from the band gap of the semiconductor to the conduction band. However, the existence of the colored organic compound enables the utilization of the solar irradiation by photosensitization process, where the colored compound could be excited by visible light and then injects an electron to the conduction band of the photocatalyst.

4. The availability of the solar energy in the Arab region can be vastly invested in the treatment of the industrial wastewater, especially the colored one. Among the different wastewater treatment techniques such as ozonation, biological treatment, Fenton's oxidation, electrochemical destruction and photosensitization, the latter was nominated to be the most preferable means.

\section{References}

1. Gardner-Outlaw and Engelman, Sustaining Water, easing Scarcity:: A Second update, Washington, D. C., Population Action International, 1997.

2. World Resources 1992-1993, Pacific Institute for Studies in: Development Environmental and Security Stockholm Environment Institute and World Bank Estimates, 1995.

3. Alnaser W E, Trieb F and Knies G, Possible cooperation between Arab and European Countries in Energy, Water and Environmental Issues, Sirse Forum, 2004 pp 99-100.

4. ESCWA Energy Options for Water Desalination in selected ESCWA members Countries, United Nations, New York, 2001.

5. Grzechulska J and Morawski A, Appl. Catal. B: Environnemental ,2002 36 (1), 45.

6. Jhon A, Jennifer T, Ken A, Heather R and Mathew T, J. Chem. Edu. 1999, 76 (12), 1680 [and references therein]. 
7. Hussein F, Mashkoor M and Al-Sharafy A, National J. Chemistry, 2003, 9: 94.

8. Li X, Liu H,. Cheng L and. Tong H, Environ. Sc. Technol., 2003 , 37 (17), 3989.

9. Vione D, Picatonitoo T and Carlotti M E, J. Cosmet Sci., 2003, 54, 513.

10. Antharjanam S, Philip R and. Suresh D, Ann. Chim., 2003,93 (9-10) , 719.

11. Fernandez-Ibanez P, Planko J, Maitato S and de las Nieres F, Water Res., 2003, 37 (13) , 3180.

12. Ohno T, Water Sci. Technol. 2004, 49 (4), 159.

13. Alkhateeb A, Hussein F and Asker K, Asian J. Chem., 2005, 17 (2), 1155.

14. Liu HL-Zhou D, Li X Z and Yue P T, J. Environ. Sci. (China), 2003, 15 (5), 595.

15. Chen J, Liu M, Zhang J, Ying X and Jin L, J. Environ. Manage, 2004, 70 (1), 43.

16. Hussein F H and. Alkhateeb A N, Desalination 2007, 209, 361.[and references therein].

17. Hongre D and Alkesson G, Water Res., 1996, 30, 2771.

18. Anaral P, Fernades D, Tarares A, Xarares A, Cammarota H, Continho J and Coelho M, Environ. Technol. 2004,25 (11) ,1313.

19. Addamo M, Augugliaro V, Coluccia S, Di Paola A, Garc'ia-Lopez E, Loddo V, GianmarioMartra G M and Palmisano L, Int. J. Photoenergy, 2006, 1.

20. Maria Hoeben W F, Ph.D thesis, Eindhoven: Technische Universiteit Eindhoven, 2000.

21. Bahnemann D, Cunnigham J, Fox M A, Pelizzetti E, Pichal P and Sorpone N, Aquatic and Surface Photochemistry, Lewis Publishers, London, 1994, p 261.

22. Topalov A, Sojic D, Molnar-Gabor D, Abramovic B and Comor M, Applied Catalysis B: Environmental , 2004, 54, 125. 


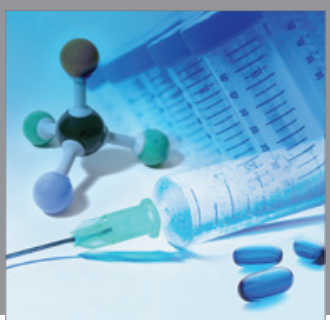

International Journal of

Medicinal Chemistry

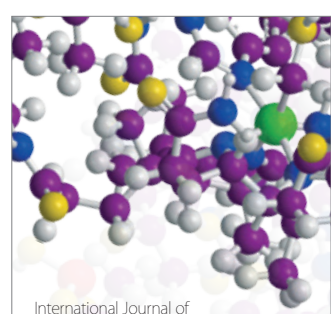

Carbohydrate Chemistry

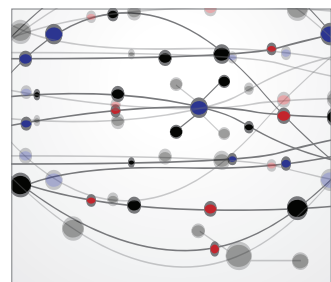

The Scientific World Journal
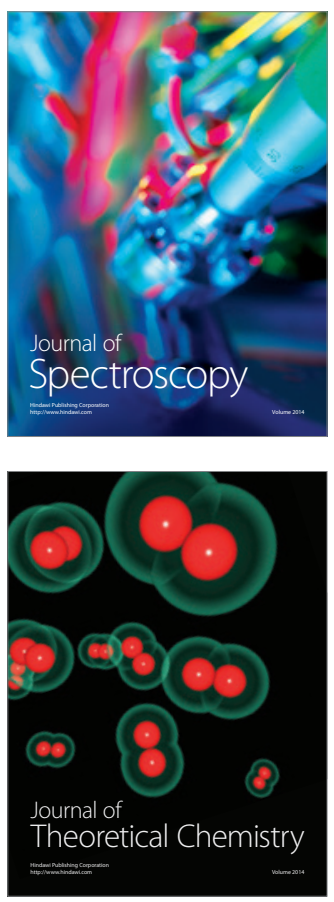
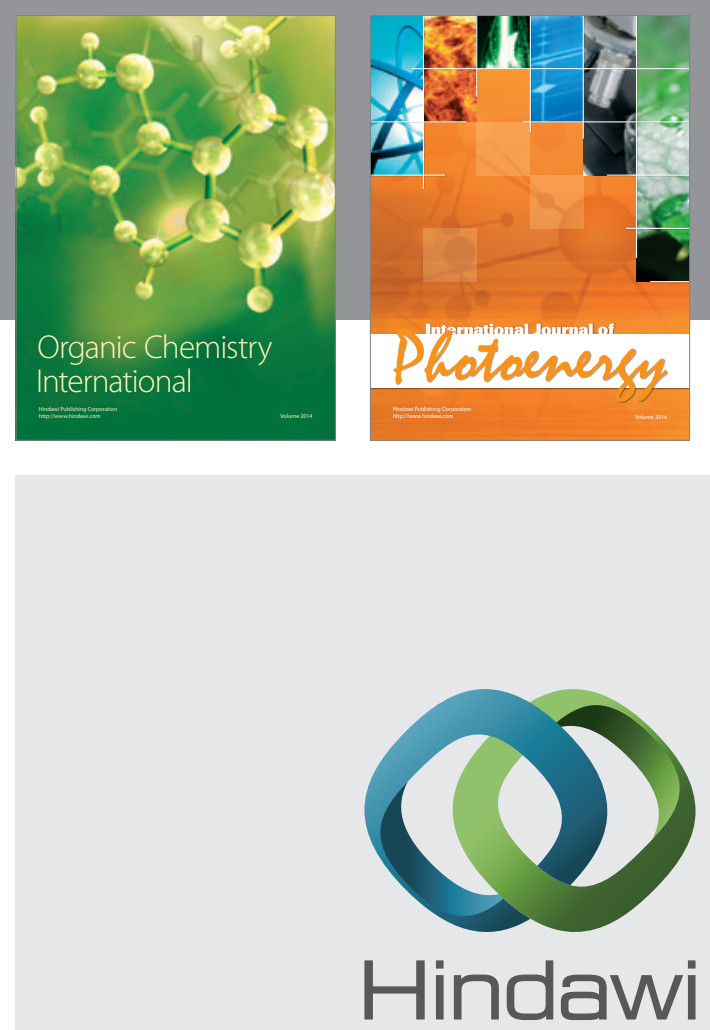

Submit your manuscripts at

http://www.hindawi.com
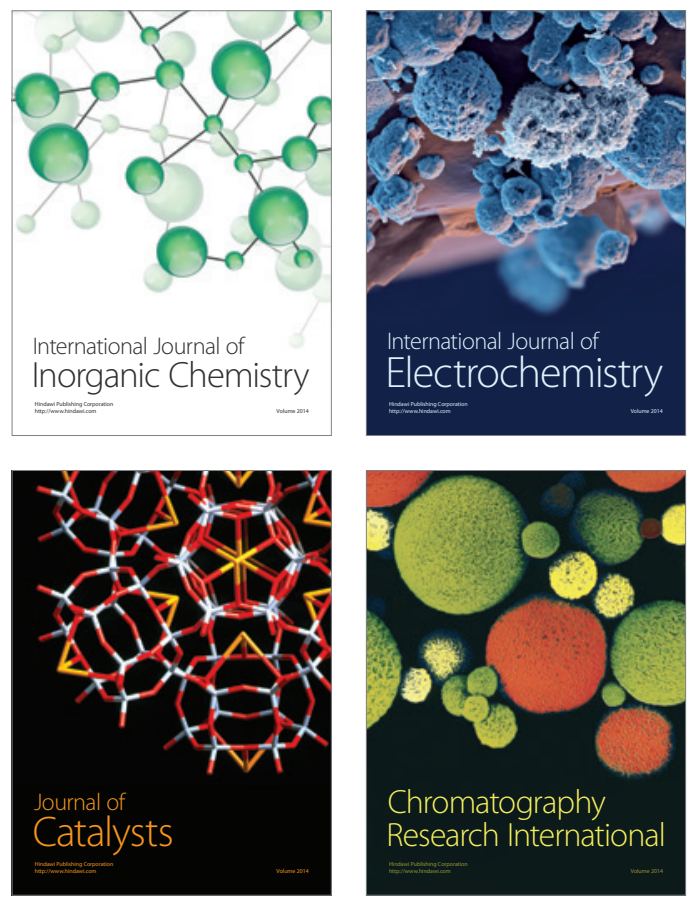
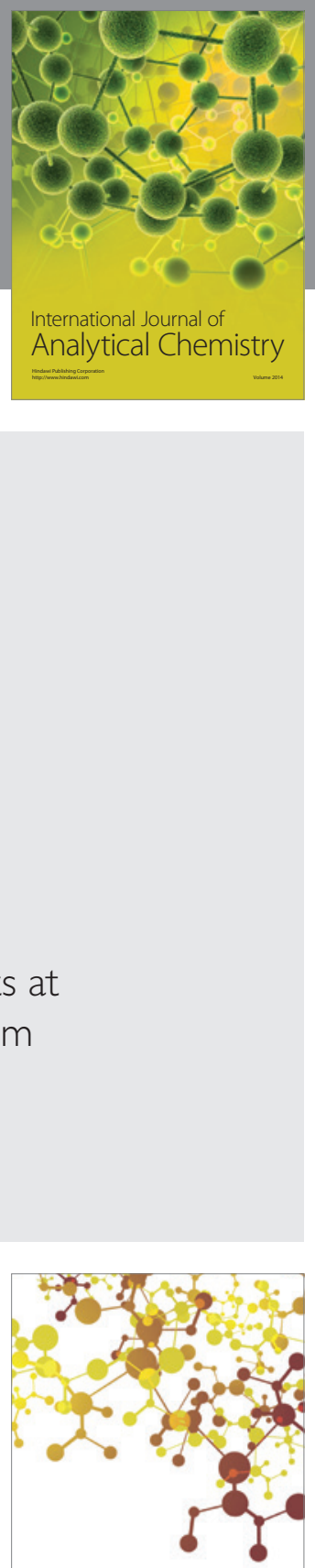

Journal of

Applied Chemistry
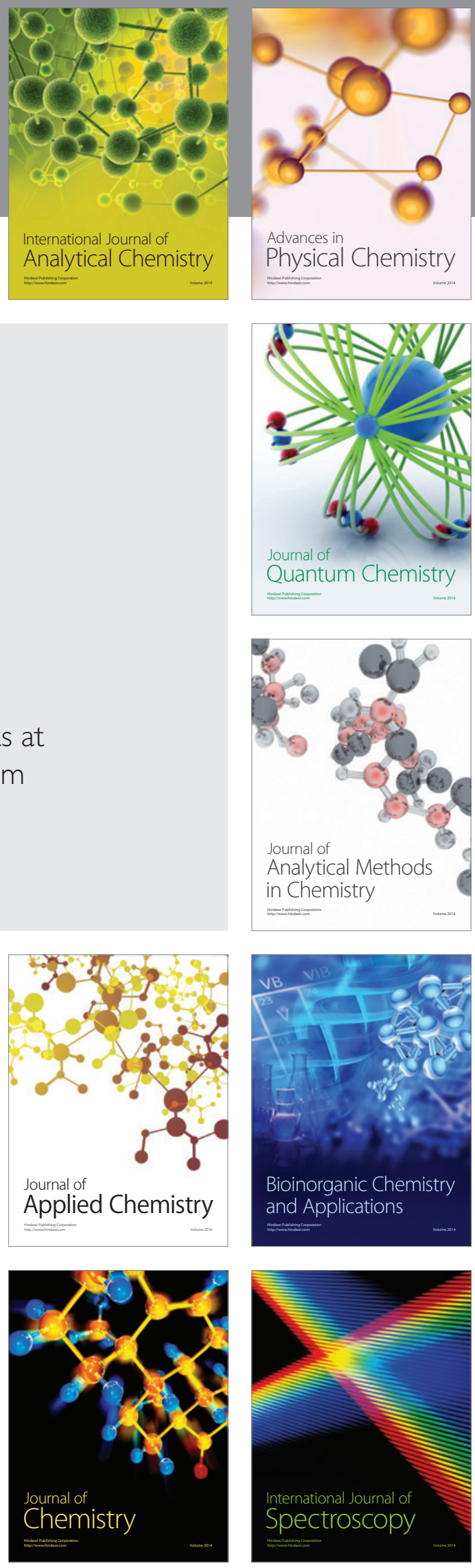